\title{
The Design of Compass/BeiDou Navigation Satellite Terminal for Migrant Bird Research
}

\author{
Yaohui Li, ${ }^{1}$ Jingjing Shan, ${ }^{2}$ Zhenhai Shao, ${ }^{3}$ and Quan Wang ${ }^{3}$ \\ ${ }^{1}$ Marine College, Shandong University, Weihai 264209, China \\ ${ }^{2}$ School of Information Science and Engineering, Shandong University, Weihai 264209, China \\ ${ }^{3}$ School of Communication and Information, University of Electronic Science Technology of China, Chengdu 611731, China
}

Correspondence should be addressed to Zhenhai Shao; shao_zh@uestc.edu.cn

Received 28 June 2014; Accepted 11 July 2014; Published 25 September 2014

Academic Editor: Wendong Xiao

Copyright (C) 2014 Yaohui Li et al. This is an open access article distributed under the Creative Commons Attribution License, which permits unrestricted use, distribution, and reproduction in any medium, provided the original work is properly cited.

\begin{abstract}
A terminal of Compass Navigation Satellite System (CNSS), which can not only support BeiDou-1 and BeiDou-2 but also support Global Positioning System (GPS), is designed to research the activities of the migrant birds, with our novel design of a multiband antenna. By a high-density integration, this terminal is designed with a compact size and light weight. When the terminal is assembled to a whooper swan, its flying trace is recorded by the CNSS, which is in agreement with that of GPS. The flying route map based on the CNSS is useful to check the situation and habit of the migrant bird, which is important for animal protection and bird flu outbreak prediction.
\end{abstract}

\section{Introduction}

Currently the bird flu, such as H7N9, transmitted and explored by the live poultries and the migrant birds which can bring avian influenza virus, is popular and almost happens in each spring in southeastern China since 2000; it forms a threat to the human health and creates great loss for the poultry industry. For example, in the years of 20042008 , over 100 outbreaks in domestic poultry occurred in 23 provinces and caused severe economic damage to the poultry industry in China [1]. Afterwards, the H5N1 virus outbreaks in poultry in 2003, 2004, and 2009 caused unprecedented geographical impact in Asia.

Advanced satellite tracking technologies have collected huge amounts of wild birds' migration data. These data are very useful for biologists to understand birds' dynamic migration patterns, to study correlations between the habitats, and to predict global spread trends of avian influenza. In the research of a migrant bird, how to get its information, such as migration time, path line, and rested site, is important for ornithology research and protection of endangered rare species. However, since the migrating time and space are so big and the resting site during migrating is so wicked, it is difficult to obtain this information. Although the traditional bird banding method is simple operation, it is dependent on long-time investigation and it is not easy to get enough information to analyze these characteristics [2].

Since 1980s, satellite tracking technique was used to study wildlife migration. At present, the major one is the French ARGOS system [3]. In this system, Tiros-N satellite receives signals which are sent out from platform transmitter terminal, measuring Doppler frequency deviation value of carrier waves to determine the location of platform transmitter terminal (PTT). Afterwards, the location information will be sent to users.

Since satellite tracking system and PTT which are applied in migrant birds still have a lot of problems, such as poor accuracy, discontinuous locating point, poor cruising ability, and high cost, the location of the study area can seriously affect performance [4]. However, self-localization is realized through BeiDou Navigation Satellite System and Global Positioning System, which can transmit location information to PTT of BeiDou-1 receiving terminal through BeiDou Satellite Navigation Experimental System (BeiDou-1). 


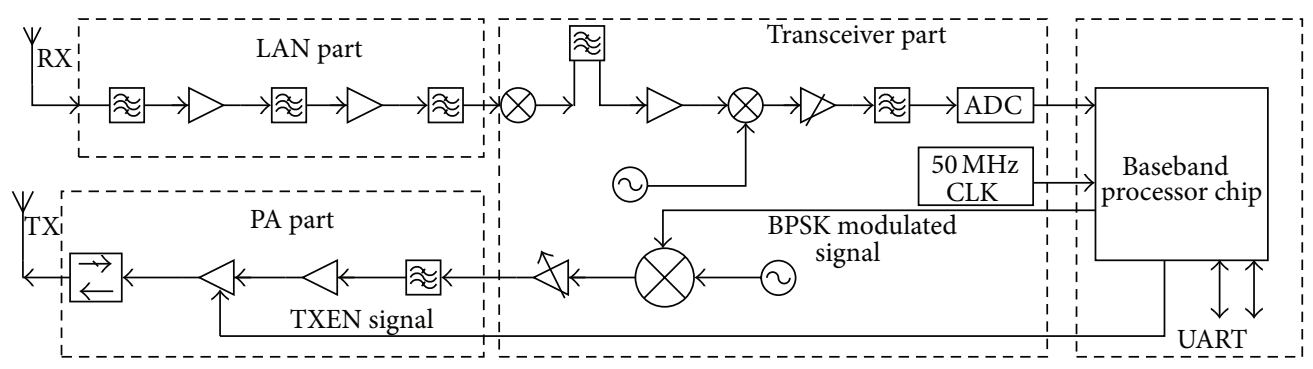

FIgURE 1: The system configuration of the BeiDou-1 terminal.

In this paper, a terminal of the CNSS is designed in Section 2, which includes system design, transceiver design, and antenna design. In Section 3, the terminal of CNSS is applied to a whooper swan to measure its trace. Finally, the paper is summarized.

\section{Design of the CNSS Terminal}

This system is mainly made of PTT, BeiDou Navigation Satellites, BeiDou-1 satellite communication receiving terminal, and data processing software adorned on migrant birds (see Figure 3). PTT uses BeiDou-2/GPS system to realize autonomous passive location. After location information is processed by a single chip, it is sent to BeiDou-1 satellite and transmitted to satellite communication receiving terminal by BeiDou-1 satellite continuously. After being received by the terminal, the data were distributed by the processing units which were then received by the researchers. This system is made of BeiDou-2/GPS bimodule positioning module, BeiDou-1 satellite communication module, quadband circularly polarized antenna, and power and control modules.

2.1. BeiDou Navigation Satellite System. BeiDou-1 is an experimental regional navigation system, which consists of four satellites (three working satellites and one backup satellite) [5]. BeiDou-1 uses satellites in geostationary orbit. Its service area is from longitude $70^{\circ} \mathrm{E}$ to $140^{\circ} \mathrm{E}$ and from latitude $5^{\circ} \mathrm{N}$ to $55^{\circ} \mathrm{N}$ [6], and its carrier frequency is $2491.75 \mathrm{MHz}$. BeiDou- 2 system will be a constellation of 35 satellites, which includes 5 geostationary orbit satellites for backward compatibility with BeiDou-1 and 30 nongeostationary satellites (27 in medium earth orbit and 3 in inclined geosynchronous orbit), that will offer complete coverage of the globe [7].

Here, the system configuration of CNSS terminal, which includes BeiDou-2/GPS Dual-mode positioning module and BeiDou-1 satellite communication module, is shown in Figures 1 and 2.

The terminal is integrated with a CNSS radio frequency transceiver chip, power amplifier chip, and baseband module so that it can realize all the functions of the CNSS. A CNSS satellite signal by the transceiver chips can be amplified by LNA, converted to intermediate frequency, and then outputted through UART port after being processed by the baseband module. At the same time, a CNSS baseband data can be produced by the baseband module after receiving

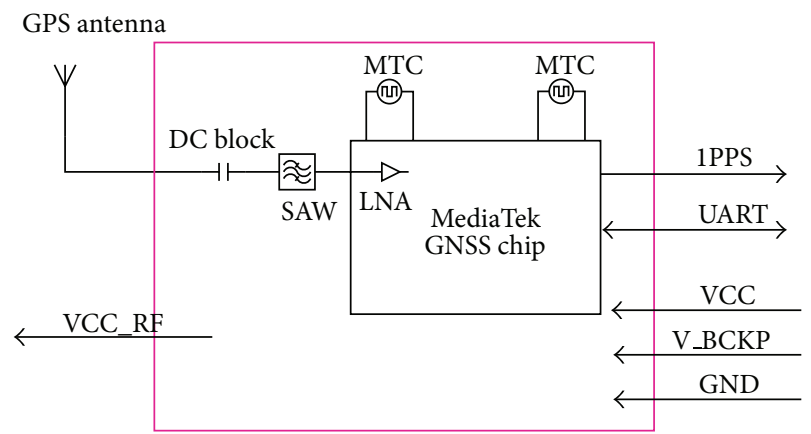

FIgURE 2: The prototype of GPS/BeiDou-2 module in the system.

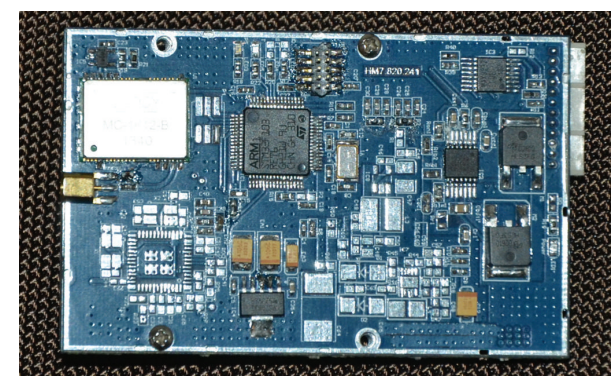

FIgURE 3: The layout of the terminal of CNSS.

UART port command. After shaping, filtering, and modulating, it can be converted to a CNSS RF signal by the transceiver chip, then amplified by a built-in amplifier, and finally radiated from an external passive antenna. The clock signals of the baseband module are also produced by the transceiver chip.

2.2. Quad-Band Circularly Polarized Antenna. In order to make the terminal work well and support these three kinds of radio systems, that is, BeiDou-1, BeiDou-2, and GPS, a multiband circularly polarized (CP) antenna is proposed to meet it.

The proposed configuration shown in Figure 4 is composed of two-layer patches, three-layer substrate, with two air layers, and a feed network. Its axial ratio bandwidth, realized gain, and antenna efficiency are improved by the air layer [8]. The down-layer is designed to support feed network, which is composed of a wideband $90^{\circ}$ quadrature hybrid coupler and a Wilkinson power divider with $90^{\circ}$ phase shift section. 

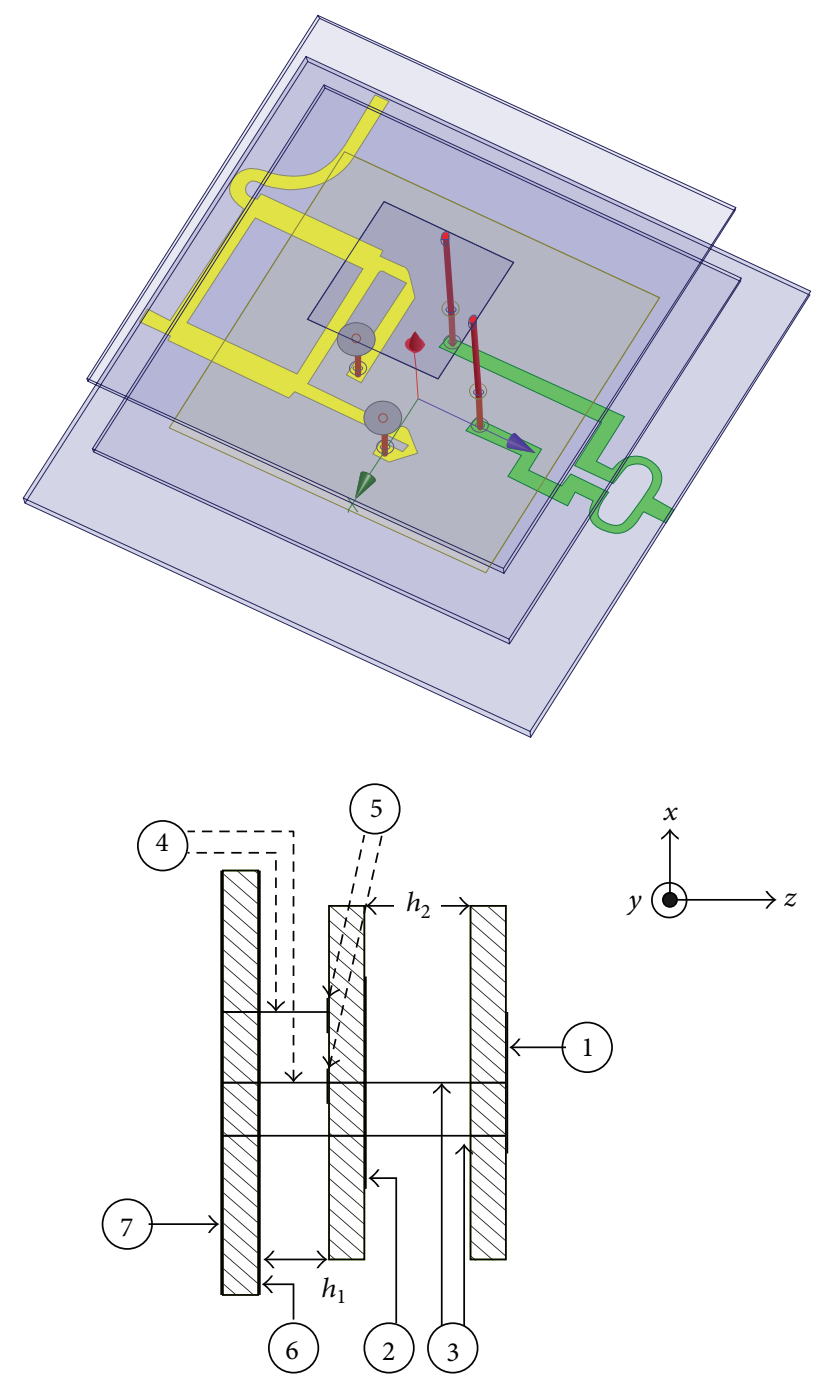
(1) Upper patch
(5) Capacitive cap
(2) Middle patch
(6) Ground
(3) Upper probe
(7) Feed network
(4) Lower probe
(8) Hole in the patch

(a) Side view

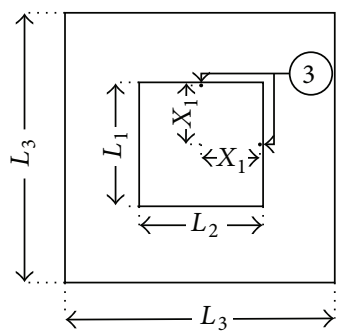

(1) Upper patch with substrate

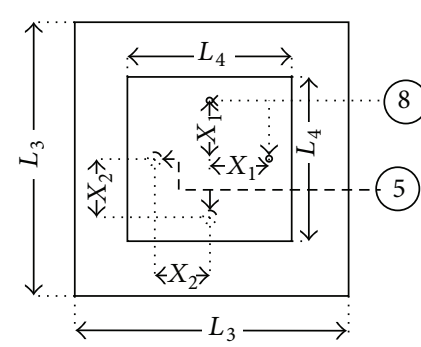

(2) Lower patch with substrate (b) Upper patch and lower patch
Double-feed is used to obtain better circular polarization purity, where the $90^{\circ}$ quadrature hybrid coupler and a Wilkinson power divider can acquire a wider impedance bandwidth. The design antenna supports two orthogonal modes which are combined in the operating band to deliver $\mathrm{CP}$ operation. The middle-layer radiating element is fed by a wideband $90^{\circ}$ quadrature hybrid coupler to obtain L1-band, $1615 \mathrm{MHz}$, and B1-band. The up-layer radiating element is fed by a Wilkinson power divider and $90^{\circ}$ phase shift section to attain suitable operation at $2491 \mathrm{MHz}$, where the Wilkinson power divider uses a $100 \mathrm{ohm}$ resistance in order to improve the isolation between dual feed for different frequency points. Because the inductive effect of the probe will deteriorate the impedance matching, a small circular capacitive cap is employed on the top of the probe to compensate for this effect. Meanwhile, the coupled probe feed structures can increase the impedance bandwidth.

The antenna patch is printed on an FR4 substrate with a relative permittivity of 4.4 and thickness of $0.2 \mathrm{~mm}$. The geometry for the proposed quad-band CP antenna is shown in Figure 4. The initial values of the effective dielectric constant are referred to as the static values, and they are given by

$$
\varepsilon_{\text {reff }}=\frac{\varepsilon_{r}+1}{2}+\frac{\varepsilon_{r}-1}{2}\left[1+12 \frac{h_{s}}{w_{l}}\right]^{-1 / 2},
$$

where $w_{l}$ is the width of the microstrip line and $h_{s}$ is the thickness of the substrate.

Because of the fringing effects, electrically the patch of the microstrip antenna looks greater than its physical dimensions. The dimensions of the patch along its length have been extended on each end by a distance $\Delta L$, which is a function of the effective dielectric constant $\varepsilon_{\text {reff }}$ and the width-to-height ratio $W / h$. A very popular and practical approximate relation for the normalized extension of the length is

$$
\frac{\Delta L}{h}=0.412 \frac{\left(\varepsilon_{\text {reff }}+0.3\right)(W / h+0.264)}{\left(\varepsilon_{\text {reff }}-0.258\right)(W / h+0.8)} .
$$

Since the length of the patch has been extended by $\Delta L$ on each side, the effective length of the patch is now $(L=\lambda / 2$ for dominant $\mathrm{TM}_{010}$ mode with no fringing)

$$
L_{\text {eff }}=L+2 \Delta L \text {. }
$$

For the dominant $\mathrm{TM}_{010}$ mode, the resonant frequency of the microstrip antenna is a function of its length. Usually it is given by

$$
f_{r}=\frac{v_{0}}{2 L \sqrt{\varepsilon_{r}}},
$$

where $v_{0}$ is the speed of light in free space. Since (4) does not account for fringing, it must be modified to include edge effects and should be computed using

$$
f_{r}=\frac{v_{0}}{2 L_{\text {eff }} \sqrt{\varepsilon_{r e f f}}}=\frac{v_{0}}{2(L+2 \Delta L) \sqrt{\varepsilon_{\text {reff }}}}=q \frac{v_{0}}{2 L \sqrt{\varepsilon_{r}}},
$$


where

$$
q=\frac{\left(f_{r c}\right)_{010}}{\left(f_{r}\right)_{010}}
$$

The $q$ factor is referred to as the fringe factor (length reduction factor). As the substrate height increases, fringing also increases and leads to larger separations between the radiating edges and lower resonant frequencies.

As long as the specified information including the dielectric constant of the substrate $\left(\varepsilon_{r}\right)$, the resonant frequency $\left(f_{r}\right)$, and the height of the substrate $h$ has been chosen, for an efficient radiator, a practical width $W$ and length $L$ can be obtained using

$$
W=\frac{1}{2 f_{r} \sqrt{\varepsilon_{0} \mu_{0}}} \sqrt{\frac{2}{\varepsilon_{r}+1}}=\frac{v_{0}}{2 f_{r}} \sqrt{\frac{2}{\varepsilon_{r}+1}} .
$$

Once $W$ is found using (7), the effective dielectric constant of the microstrip antenna using (1) and the extension of the length $\Delta L$ using (2) can be determined. The actual length of the patch can now be determined by

$$
L=\frac{1}{2 f_{r} \sqrt{\varepsilon_{0} \mu_{0}} \sqrt{\varepsilon_{r e f f}}}-2 \Delta L .
$$

To achieve a good performance, such as gain, axial ratio, return loss, and isolation, all the parameters are optimized in the commercial simulation software. The optimized structure parameters are as follows: $L_{1}=28.4 \mathrm{~mm}, L_{2}=27.6, L_{3}=$ $88 \mathrm{~mm}, L_{4}=66.6 \mathrm{~mm}, X_{1}=13 \mathrm{~mm}, X_{2}=12.6 \mathrm{~mm}, h_{1}=$ $10.3 \mathrm{~mm}, h_{2}=24.1, \mathrm{cp}_{1}=3 \mathrm{~mm}, \mathrm{cp}_{2}=25.2 \mathrm{~mm}, \mathrm{cp}_{3}=$ $22.85 \mathrm{~mm}, \mathrm{cp}_{4}=5.06 \mathrm{~mm}, j_{1}=3 \mathrm{~mm}, j_{2}=1.5 \mathrm{~mm}$, and $j_{3}=6.4 \mathrm{~mm}$; the diameter of capacitive cap is $7.2 \mathrm{~mm}$.

After simulation and fabrication, the antenna is measured. It is shown in Figure 5 that the return loss curve of the measured results is close to that of the simulated results. The measured impedance bandwidths of $-10 \mathrm{~dB}$ return loss for the $1561 \mathrm{MHz}, 1575 \mathrm{MHz}, 1615 \mathrm{MHz}$, and $2491 \mathrm{MHz}$ are $300 \mathrm{MHz}$ (or 19\%), $260 \mathrm{MHz}$ (or 16\%), and $480 \mathrm{MHz}$ (or $19 \%)$, respectively. The bandwidths of $2 \mathrm{~dB}$ axial ratio at $1561 \mathrm{MHz}, 1575 \mathrm{MHz}, 1615 \mathrm{MHz}$, and $2491 \mathrm{MHz}$ are about $100 \mathrm{MHz}$ (or 6.4\%), $60 \mathrm{MHz}$ (or 3.7\%), and $100 \mathrm{MHz}$ (or $4 \%$ ), respectively. The measured realized gains at $1561 \mathrm{MHz}$, $1575 \mathrm{MHz}, 1615 \mathrm{MHz}$, and $2491 \mathrm{MHz}$ are about $6.7 \mathrm{~dB}, 6.6 \mathrm{~dB}$, $6.2 \mathrm{~dB}$, and $6.7 \mathrm{~dB}$, respectively.

\section{CNSS Measurement}

The final CNSS terminal to track the migrant birds is shown as in Figure 6.

The terminal is integrated with antenna, transceivers module, and baseband signal proceeding module. When the terminal is trying to connect with CNSS satellite in the opening area, after 10 seconds, the data link performance in Figure 7 shows that this terminal has successfully built connection with 6 CNSS satellites and 11 GPS satellites. The final system performance is shown in Table 1 .

When this terminal is used for the migrant birds, there will be different complicated conditions when birds are

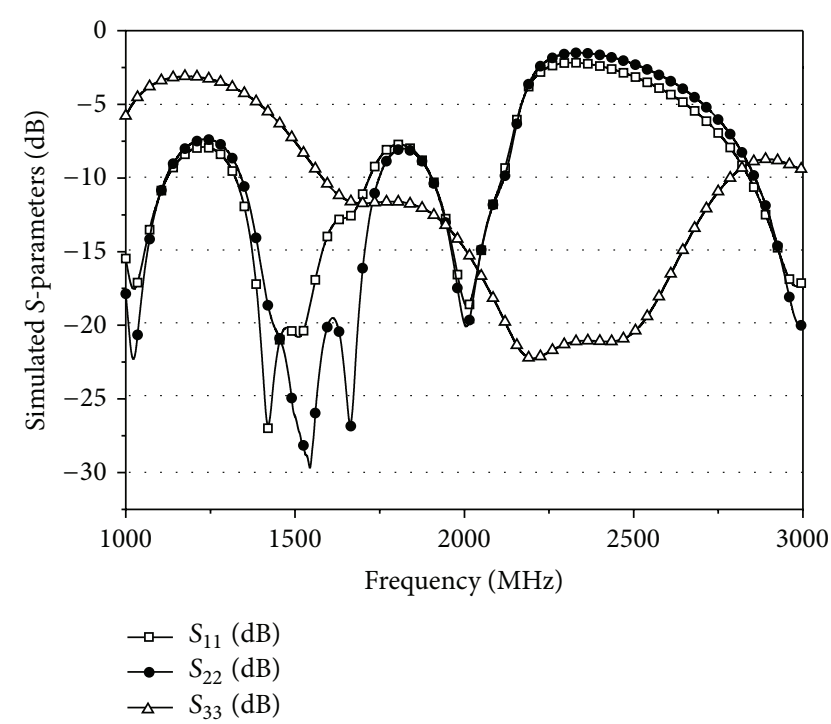

(a)

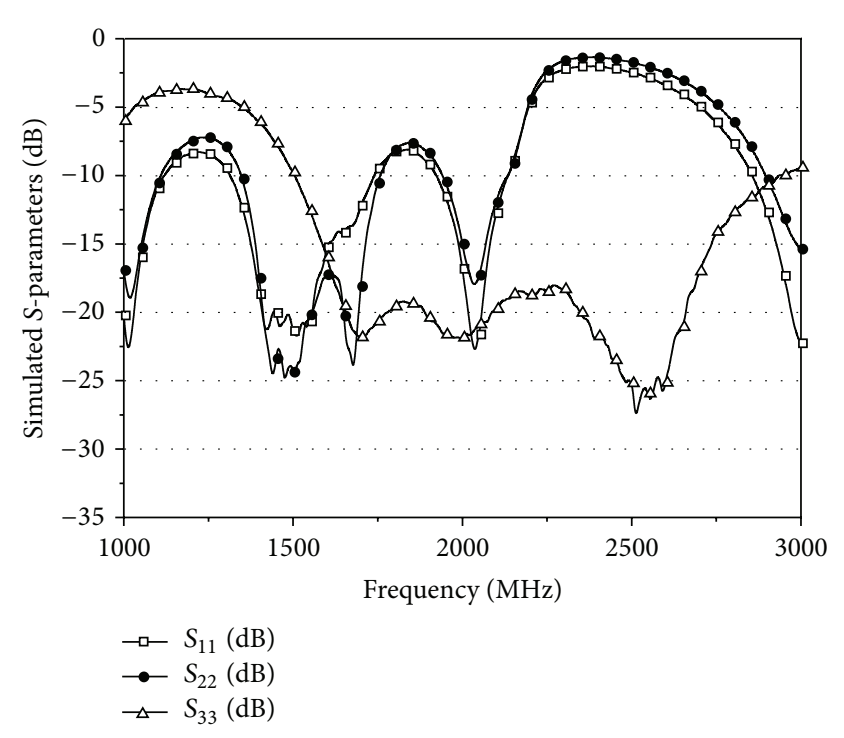

(b)

FIGURE 5: Simulated and measured $S$-parameters of the quad-band $\mathrm{CP}$ antenna in (a) and (b).

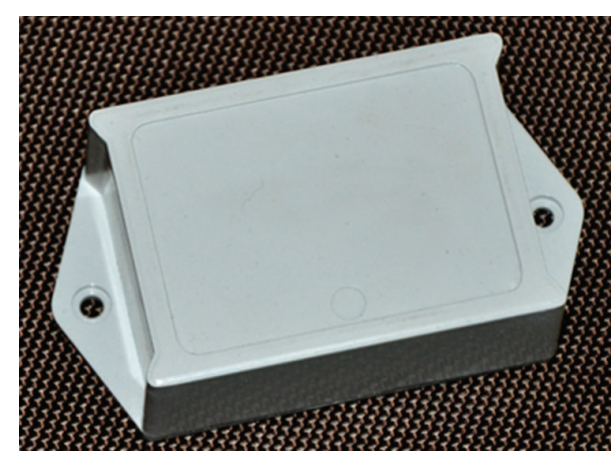

Figure 6: The photo of the CNSS terminal. 


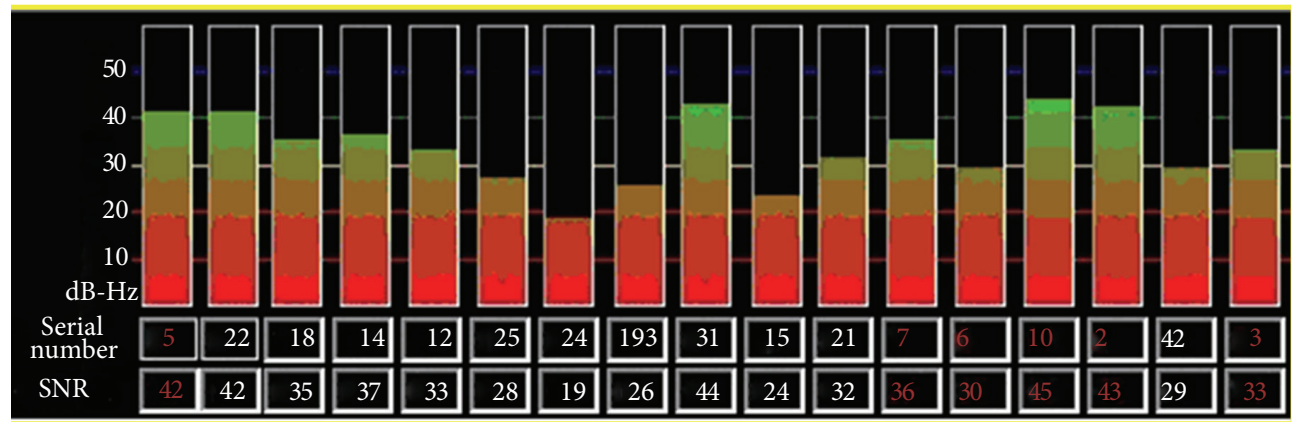

FIGURE 7: The SNR distribution of CNSS and GPS satellites.

TABLE 1: The measured parameters of the terminal.

\begin{tabular}{ll}
\hline $\begin{array}{l}\text { Input VSWR } \\
\text { Signal sensitivity of the }\end{array}$ & $\leqq 2.0$ \\
receiver & $-127.6 \mathrm{dBm}$ \\
Transmitted power & $37 \mathrm{dBm}$ \\
Carrier compression & $\geqq 30 \mathrm{dBc}$ \\
Modulated phase error & $\leqq 3^{\circ}$ \\
Localization and & Successful rate is larger than $95 \%$ and \\
communication & localization accuracy is less than \\
(continuously for 24 hours) & $100 \mathrm{~m}$ \\
& First locking time: $\leq 2 \mathrm{~s}$ \\
Locking time & Relocking time: $\leq 1 \mathrm{~s}$ \\
& Autolocalization time: $\leq 2 \mathrm{~min}$ \\
\hline
\end{tabular}

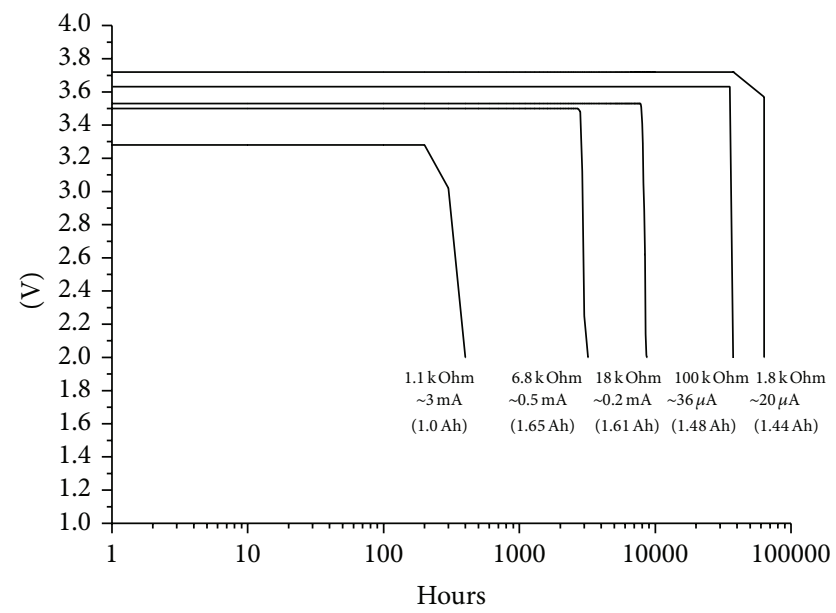

FIgURE 8: Discharge performance of battery.

migrating. Since PTT can hardly be recycled [9], battery has a significant influence on the performance of PTT. In order to improve the lifetime of PTT and meet the requirement that PTT needs strong pulse current power when transmitting signals, battery must be capable of working for a long time stably and discharging at a high power in a short time. Thus, PTT applies two pieces of TLP-96311/A/SM lithium thionyl chloride cells which are produced by Tadiran (see Figure 8). The operating voltage of the battery keeps a significant stabilization condition in the whole service life duration. This

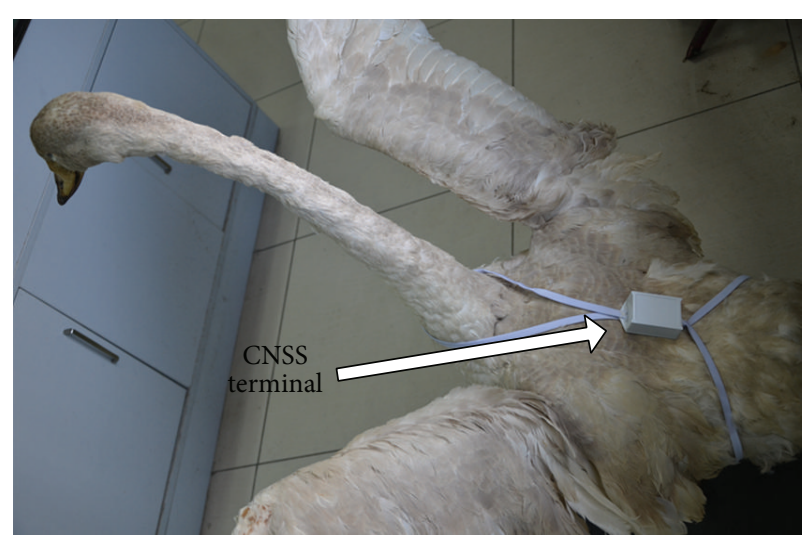

FIGURE 9: The CNSS terminal is assembled to the whooper swan.

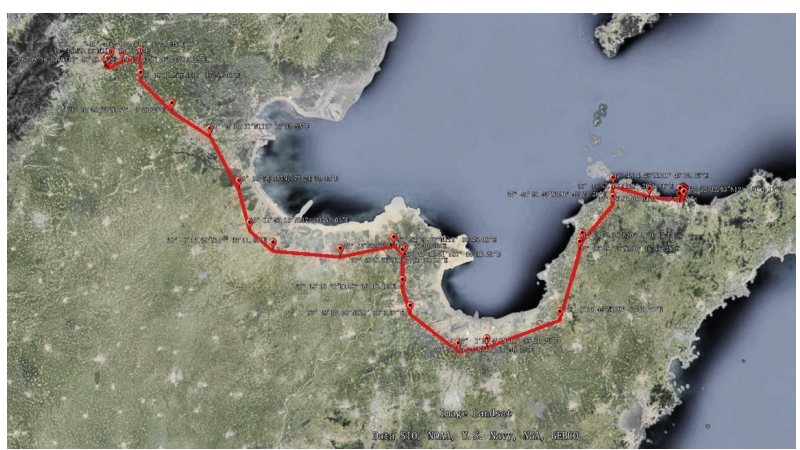

FIGURE 10: The flying trace of the whooper swan.

battery can be used in the temperature range from $-55^{\circ} \mathrm{C}$ to $+85^{\circ} \mathrm{C}$, and it is adaptable to the possible low temperature during the migration period of migrant birds. This battery has a high energy density (to $700 \mathrm{WH} / \mathrm{KG}$ and $1380 \mathrm{WH} / \mathrm{L}$ ), and it plays an important role in controlling the volume of PTT and improving cruising ability. Besides, it can make battery produce fast voltage and powerful pulse current power so as to adapt to the strong pulse current power when BeiDou-1 module is transmitting. The Li-ion battery has a feature of especially low self-discharge. Meanwhile, sealing technique is also adopted for manufacturing. Thus, it is verified from the expiration date of this battery that it can be used for more than 10 years at room temperature [10]. 


\section{Application for the Migrant Birds}

The designed terminal of CNSS is assembled to a whooper swan, which is provided by the organization of the Shunyi Protected Wetland Park. Here a photo is shown as in Figure 9.

Where the terminal of CNSS is put on the back of the whooper swan with the elastic band which is made by degradable material, its antenna, battery, and transceiver are covered by an antirain box.

After the assemble work is finished, the whooper swan is released from the Protected Wetland Park and its flying trace is investigated by the CNSS control center. From the digital map provided by the CNSS control center, the flying trace of the whooper swan is shown as in Figure 10, which can match the data obtained from our artificial observation points.

\section{Conclusion}

In this paper, the CNSS terminal is designed to obtain the flying trace of the whooper swan, which can be used to get its information, such as migration time, path line, and rested site, in order to protect these endangered rare species. With our own design of the antenna and transceiver, the CNSS terminal can work very well. It is important to mention that our system has the tremendous potential in ocean animal observation, intelligent transport systems, and disaster rescue.

\section{Conflict of Interests}

The authors declare that there is no conflict of interests regarding the publication of this paper.

\section{Acknowledgment}

This work is supported by the Shunyi Protected Wetland Park.

\section{References}

[1] L. Yao, E. Chen, Z. Chen, and Z. Gong, "From SARS to H7N9: the mechanism of responding to emerging communicable diseases has made great progress in China," BioScience Trends, vol. 7, no. 6, pp. 290-293, 2013.

[2] H. Bub, Bird Trapping and Bird Banding: A Handbook for Trapping Methods All over the World, 2012.

[3] S. G. Fancy, L. F. Pank, D. C. Douglas, C. H. Curby, and G. W. Garner, "Satellite telemetry: a new tool for wildlife research and management," DTIC Document, 1988.

[4] M. Dubinin, A. Lushchekina, and V. C. Radeloff, "Performance and accuracy of Argos transmitters for wildlife monitoring in Southern Russia," European Journal of Wildlife Research, vol. 56, no. 3, pp. 459-463, 2010.

[5] C. Wang, Y. Liu, Q. Li, and D. Huo, "Development and realization about the embedded GIS in vehicles based on ReWorks," in Applied Informatics and Communication, pp. 376-382, Springer, Berlin, Germany, 2011.

[6] C. Chong, "Status of COMPASS/BeiDou development," in Proceedings of the PNT Challenges and Opportunities Symposium, 2009.
[7] C. Han, Y. Yang, and Z. Cai, "BeiDou Navigation Satellite System and its time scales," Metrologia, vol. 48, no. 4, pp. S213S218, 2011.

[8] M. Shahabadi, D. Busuioc, A. Borji, and S. Safavi-Naeini, "Low-cost, high-efficiency quasi-planar array of waveguide-fed circularly polarized microstrip antennas," IEEE Transactions on Antennas and Propagation, vol. 53, no. 6, pp. 2036-2043, 2005.

[9] A. D. Lowther, R. G. Harcourt, D. J. Hamer, and S. D. Goldsworthy, "Creatures of habit: foraging habitat fidelity of adult female Australian sea lions," Marine Ecology Progress Series, vol. 443, pp. 249-263, 2011.

[10] P. Dan, E. Mengeritsky, D. Aurbach, I. Weissman, and E. Zinigrad, "More details on the new $\mathrm{LiMnO}_{2}$ rechargeable battery technology developed at Tadiran," Journal of Power Sources, vol. 68, no. 2, pp. 443-447, 1997. 


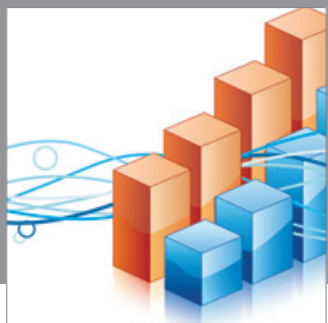

Advances in

Operations Research

mansans

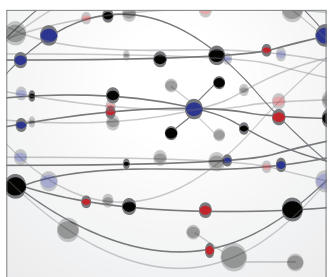

The Scientific World Journal
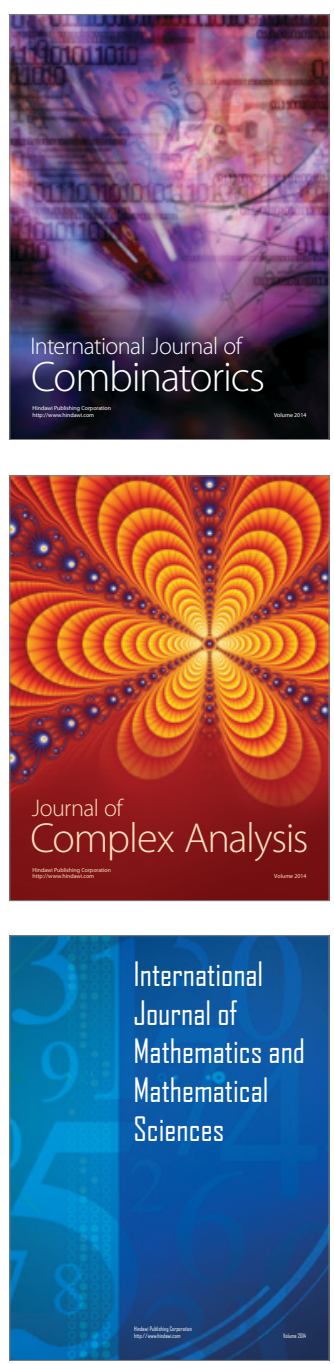
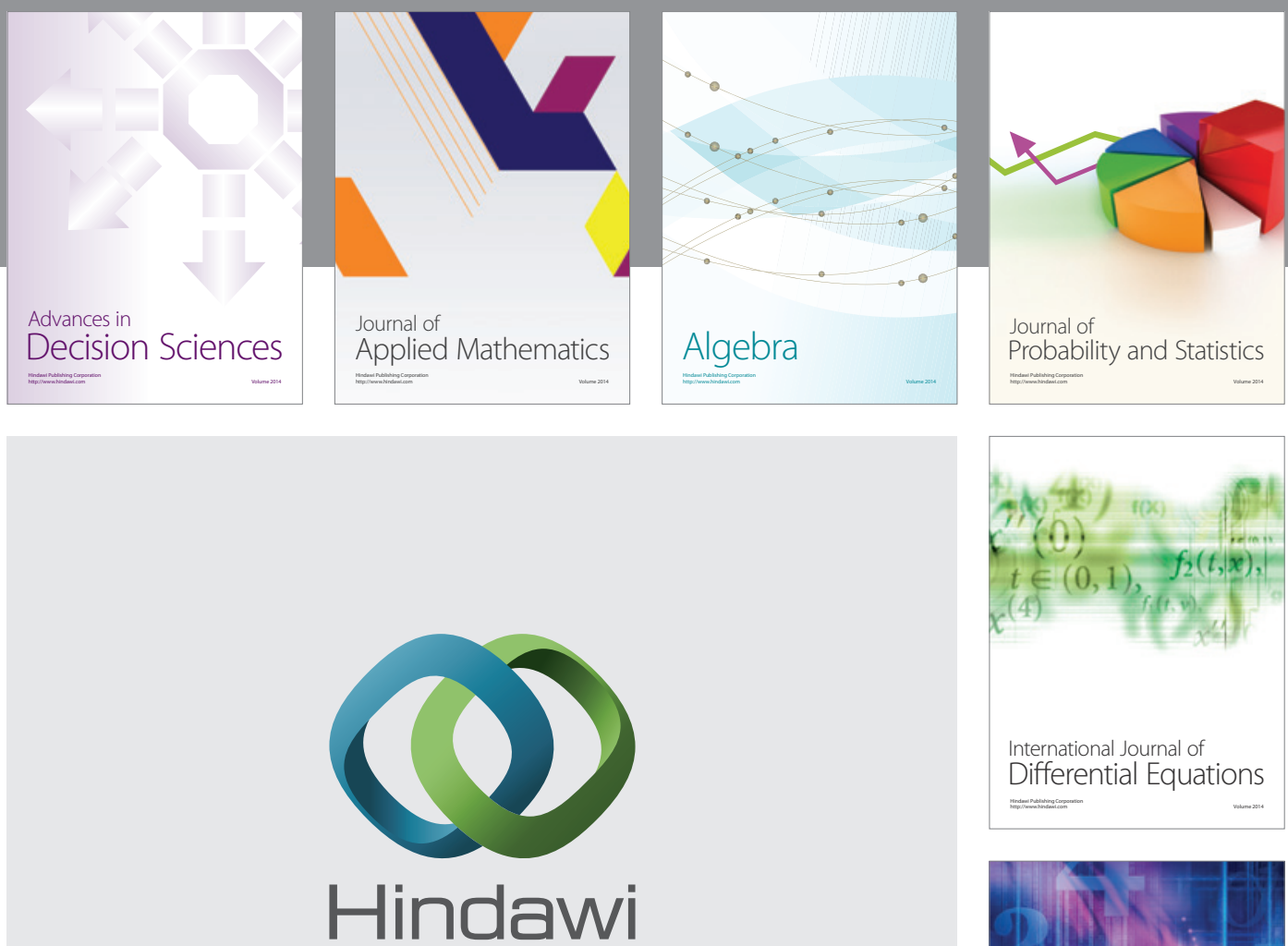

Submit your manuscripts at http://www.hindawi.com
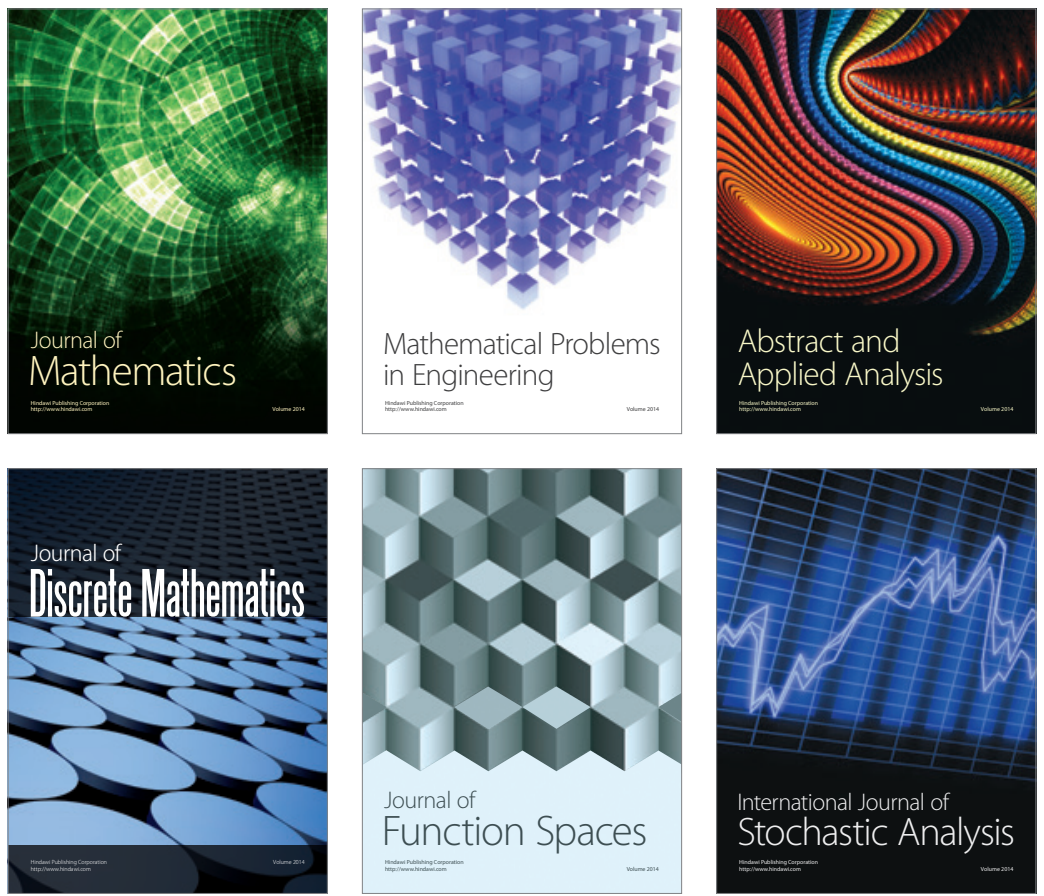

Journal of

Function Spaces

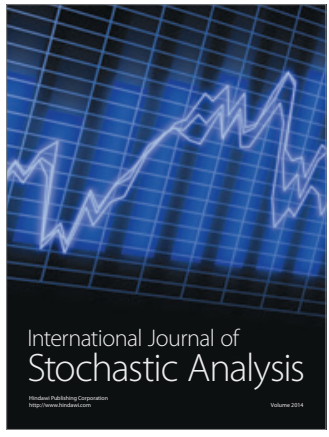

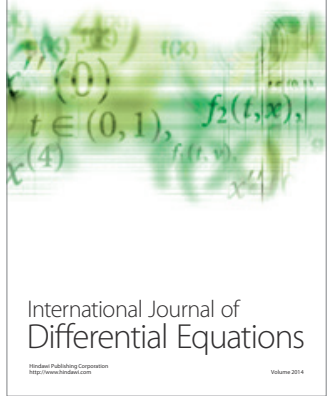
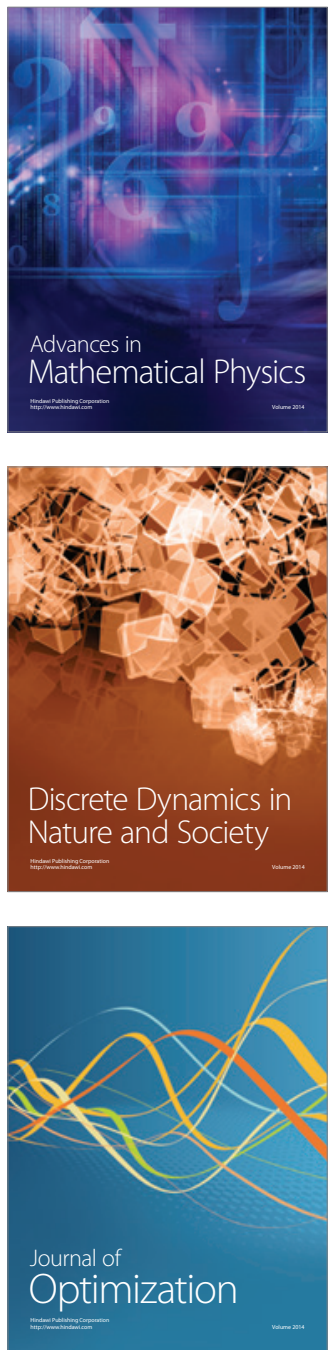